\title{
Influence of shear rate, organic matter content, pH and salinity on mud flocculation
}

\author{
Francesca Mietta - Claire Chassagne • \\ Andrew J. Manning • Johan C. Winterwerp
}

Received: 15 December 2008 / Accepted: 1 September 2009 / Published online: 25 September 2009

(C) The Author(s) 2009. This article is published with open access at Springerlink.com

\begin{abstract}
The purpose of this paper is to establish a relation between a few measurable quantities (the socalled $\zeta$ potential, organic matter content, and shear rate) and the flocculation behavior of mud. The results obtained with small-scale flocculation experiments (mixing jar) are compared to results of large-scale experiments (settling column). The mud used for all experiments has been collected in October 2007 in the lower Western Schelde, near Antwerp, Belgium. From this study, it was found that the mean floc size and the Kolmogorov microscale vary in a similar way with the shear rate for suspensions with different $\mathrm{pH}$ and salt concentrations. The size of flocs at a given shear
\end{abstract}

Responsible Editor: Alejandro Jose Souza

F. Mietta $(\bowtie) \cdot$ C. Chassagne · J. C. Winterwerp

Environmental Fluid Mechanics,

Faculty of Civil Engineering and Geosciences,

Delft University of Technology,

Box 5048, 2600 GA, Delft, The Netherlands

e-mail: f.mietta@tudelft.nl

\section{A. J. Manning}

Coastal Processes Research Group,

Marine Institute of the University of Plymouth,

School of Earth, Ocean and Environmental Sciences,

University of Plymouth, Portland Square Building (A504),

Plymouth, Devon, PL4, 8AA, UK

\author{
A. J. Manning \\ Coasts and Estuaries Group, HR Wallingford Ltd, \\ Howbery Park, Wallingford OX10 8BA, UK \\ J. C. Winterwerp \\ Deltares, Rotterdamseweg 185, \\ Postbus 177, 2600 MH, Delft, The Netherlands
}

rate depends on the properties of the suspension, which affect the electrokinetic properties of the sediment; these can be described by means of the $\zeta$ potential. The main findings of this paper are: (1) In saline suspensions at $\mathrm{pH}=8$, the mean floc size increases when the salt concentration and the $\zeta$ potential increase. (2) For a given $\zeta$ potential, the mean floc size at low $\mathrm{pH}$ is larger than observed at $\mathrm{pH}=8$ for any added salt. (3) The mean floc size increases with increasing organic matter content. (4) Mud with no organic matter at $\mathrm{pH}=8$ and no added salt flocculates very little. The response of mud suspensions to variations in salinity and $\mathrm{pH}$ is similar to that of kaolinite. This suggests that a general trend can be established for different and complex types of clays and mud. This systematic study can therefore be used for further development of flocculation models.

Keywords Flocculation $\cdot$ Natural mud $\cdot \zeta$ potential $\cdot$ Electrokinetics $\cdot$ Western Scheldt, Antwerp, Belgium

\section{Introduction}

One of the parameters used in sediment transport modeling is the settling velocity. For cohesive sediment, the settling velocity is affected in a complex way by the sediment properties and the environmental conditions through the process of flocculation. Flocculation can be regarded as a competition between aggregation and breakup. The rate at which flocs grow and the size they attain depend on hydrodynamic conditions, residence time, sediment properties, $\mathrm{pH}$, and salinity. All these quantities are highly variable in estuaries, where fresh river water mixes with salty marine water, and where 
the tidal forcing induces variations in shear rate. Burton and Liss (1976) observed that the organic matter content (OMC) is one order of magnitude higher in coastal seas $(\approx 10 \mathrm{mg} / \mathrm{l})$ than in rivers $(\approx 1 \mathrm{mg} / \mathrm{l})$. Seasonal variations of the OMC have been observed by Mikkelsen (2002).

It is technically difficult and costly to monitor cohesive sediment flocculation behavior in situ, and we seek tools to predict this behavior. Therefore, we seek laboratory investigations and process modeling that can be used to establish relations between relevant parameters, easily measurable in situ, and this behavior.

The rate of aggregation and the strength of flocs depend on the electrical charge of/on the particles. This charge is often expressed in terms of an electric potential defined as the $\zeta$ potential (Kruyt 1983), although the relation between the surface charge of particles and their $\zeta$ potential is complex (Chassagne et al. 2009). As a rule of thumb, uniformly charged particles with lower $\zeta$ potential (in absolute value) are more likely to aggregate than particles with a higher $\zeta$ potential. However, the charge of mud or clay particles is not uniform and it depends on the suspending medium properties. For instance, at $\mathrm{pH}=4$, the edges of kaolinite and montmorillonite are positively charged, which leads to fast aggregation and to the formation of larger flocs than at $\mathrm{pH}=8$, when both edges and faces are negatively charged (Tombacz and Szekeres 2004; Tomback and Szekeres 2006).

A suspension where particles are likely/unlikely to aggregate is referred to as unstable/stable. Dissolved (counter) ions can either adhere to the charged particles surface or screen its charge. An increase in salt concentration decreases the particles' charge and, therefore, would lead to an increase in the floc size; however, this is not always observed in situ. While van Leussen (1999) measured, in the Ems estuary, an increase of the floc size for increasing salinity, Eisma et al. (1991) observed a decrease of the floc size for increasing salinity. Burt (1986) carried out a large series of floc size measurements at different salinities within the Thames estuary, but could not find any correlation between salinity and floc size. In situ variations of salinity are associated with variations of the shear rate, sediment concentration, and $\mathrm{OMC}$, and it is therefore difficult to establish the effect of each of these physical quantities independently. Moreover, the effect of salinity is also influenced by the history of flocs. Although a few authors performed flocculation experiments on natural sediment at different salinities (van Leussen 1999), mud flocculation has not been related to the electrokinetic properties ( $\zeta$ potential) of the sediment in a systematic way.
To give an order of magnitude, the salinity changes from 0 to 33 parts per thousand (ppt) in estuaries while the $\mathrm{pH}$ is rather constant $(\mathrm{pH} \approx 7-8)$. However, to determine the relation between the charge of the particles and their flocculation behavior, we investigate a wider range of salinity and $\mathrm{pH}$. The surface charge of clays is $\mathrm{pH}$-sensitive. By using different $\mathrm{pH}$ values, we can study the flocculation kinetics for particles with different surface charges (Tomback and Szekeres 2006).

Organic matter consists mainly of polymers (Winterwerp and van Kesteren 2004); it is a major factor responsible for mud flocculation since it can adhere to particles modifying their surface charge. Long polymers may adhere to two different particles through the so-called bridging. An increase of the OMC leads, therefore, to an increase of the floc size, as observed by van der Lee (2000) and Mikkelsen (2002).

In the first part of this article (Section 3.1), we investigate the variation of floc size with shear rate for a few different suspensions (different $\mathrm{pH}$ and salinity). In the second part (Sections 3.3 and 3.4), we investigate the variation of floc size for a wide range of $\mathrm{pH}$, salinity, and OMCs at a specific shear rate.

In the third part (Section 4), we compare small-scale and large-scale flocculation experiments. We use two different laboratory devices: small-scale mixing jars and a large-scale settling column. The mixing jar experiments enable us to investigate high shear rates (Mietta et al. 2009), whereas settling column experiments yield both low and high shear rates (Maggi et al. 2002).

\section{Materials and methods}

\subsection{Materials}

We used mud from the lower Western Scheldt, sampled in October 2007. The major clay components of the Western Scheldt mud are illite $(53 \%)$, smectite or montmorillonite $(21 \%)$, and kaolinite $(26 \%)$ (Fettweis et al. 2006). The OMC measured by loss on ignition is $6.6 \%$ by mass; $2 \%$ by mass of the material is less than $2 \mu \mathrm{m}$, and $93 \%$ is less than $63 \mu \mathrm{m}$. The $\mathrm{pH}$ of the suspension with mud and tap water is modified by adding hydrochloric acid, $\mathrm{HCl}$. $\mathrm{NaCl}$ and $\mathrm{MgCl}_{2}$ are used to investigate the effect of monovalent and divalent salt. Artificial sea salt is prepared as a composition of its four major components: $\mathrm{KCl}, \mathrm{NaCl}$, $\mathrm{MgCl}_{2}$, and $\mathrm{CaCl}_{2}$. The salt concentration is expressed in ppt. To remove organic matter, the mud has been treated with hydrogen peroxide following the protocol in Leifeld and Kogel-Knabner (2001). Suspensions with different $\mathrm{OMC}$ are obtained mixing untreated mud 
with mud treated with hydrogen peroxide at different ratios. Where not otherwise specified, the term "mud" refers to untreated mud. We also used kaolinite (China clay) $\mathrm{Al}_{2} \mathrm{O}_{3}-2 \mathrm{SiO}_{2}-2 \mathrm{H}_{2} \mathrm{O}$ from (VE-KA, The Netherlands); see Mietta et al. (2009) for details.

\section{$2.2 \zeta$ potential}

The $\zeta$ potential has been estimated from electrophoretic measurements (Malvern Zetasizer 1000HS/ $3000 \mathrm{HS}$ ) using the Smoluchowski equation. As discussed in Chassagne et al. (2009), the magnitude of the $\zeta$ potential using this formula may not be correct. However, we will show that, as for kaolinite, the variation of the Smoluchowski $\zeta$ potential with the properties of the suspension provides useful information for the flocculation behavior.

The $\zeta$ potential is a property of a single particle, and it is not affected by the sediment concentration. For electrophoretic measurements, the sediment concentration needs to be low enough to ensure that there is no electrostatic interaction between the particles. All $\zeta$ potential measurements shown in this article are done at a mud concentration $c=0.05 \mathrm{~g} / \mathrm{l}$. We checked that this concentration was low enough to ensure that there is no electrostatic interaction between the particles.

\subsection{Small-scale flocculation experiments: mixing jar}

We used jars of $125 \mathrm{~mm}$ diameter and $85 \mathrm{~mm}$ height, equipped with four $12 \mathrm{~mm}$-wide baffles to increase and homogenize the shear rate. The suspension is stirred using a single rectangular paddle, which is placed $10 \mathrm{~mm}$ above the bottom of the jar. The paddle is $25 \mathrm{~mm}$ high and $75 \mathrm{~mm}$ in diameter.

The average shear rate in the jar for each stirring frequency can be determined measuring the power dissipation of the propeller $P$ (Bouyer et al. 2005; Nagata 1975). If $V$ is the volume of the suspension, the power dissipation per unit volume $P_{v}=P / V$ can be related to the turbulent energy dissipation parameter $\epsilon$ as $\epsilon \rho_{w}=$ $P_{v} g_{c}$, where $g_{c}$ is the centrifugal acceleration of the propeller and $\rho_{w}$ is the fluid density. The shear rate for each stirring frequency can be derived from the dissipation parameter by (Tennekes and Lumley 1972):

$G=\sqrt{\frac{\epsilon}{v}}=\sqrt{\frac{P_{v} g_{c}}{\rho_{w} v}}$,

where $v$ is the viscosity of the fluid. The power number $N_{p}$ of a propeller can be expressed as a function of the power dissipation $P$, the stirring frequency in rotations per seconds $n$, and the diameter of the propeller $d$ as follows (Nagata 1975):

$N_{p}=\frac{P g_{c}}{\rho_{w} n^{3} d^{5}}$.

Substituting Eq. 2 into Eq. 1, the shear rate can be defined as a function of the power number:

$G=\sqrt{\frac{N_{p} d^{5} n^{3}}{V v}}$.

By measuring the power dissipation of the propeller $P$, a relation between $G$ and the stirring frequency $n$ has been derived for the jar used in our experiments (KIWA 1976): $\log G=-0.849+1.5 \log (60 n)$, where $n$ is expressed in rotations per second. This relation has been verified for $n \in[0,9] \mathrm{rps}$. On the basis of a large number of experiments, Nagata (1975) proposed an empirical relation to compute the power number from the geometry of the jar and the propeller. The shear rate obtained from the measurements of the power consumption and that obtained using the empirical equation proposed by Nagata (1975) differ not more than $5 \%$ for $G \leq 101 \mathrm{~s}^{-1}$.

The volume-based floc size distributions within the jar are measured every 20-30 min through laser diffraction with a Malvern Mastersizer 2000. The size range covered by the instrument is from $10 \mathrm{~nm}$ to $10 \mathrm{~mm}$. Samples are taken from the mixing jar $20 \mathrm{~mm}$ below the water surface by means of a peristaltic pump. The pump is located after the measuring section, and the diameter of the tube connecting the jar to the measuring section is $6 \mathrm{~mm}$; the flow rate is set to $0.1 \mathrm{l} / \mathrm{min}$ corresponding to a Reynolds number of 350 in the tube. At this flow rate, we checked that particles do not settle in the tube, but that flocs are not disrupted either.

All experiments started from a deflocculated suspension obtained by stirring for $3 \mathrm{~min}$ at $G=400 \mathrm{~s}^{-1}$. We verified that this is sufficient to deflocculate the suspension by comparing the floc size distribution after stirring to the one after ultrasonic treatment. All flocculation tests have been carried out at mass concentration $c=0.12 \mathrm{~g} / \mathrm{l}$. Tests are continued until a steady state has been reached, and the average floc size remains constant in time. Although the floc size varies very little after $2 \mathrm{~h}$ from the beginning of the experiments, tests are continued for $5 \mathrm{~h}$ to ensure a steady state. At low shear rate, experiments were stopped before reaching this steady state, as mean size and sediment concentration started to decrease because of particle settling. 


\subsection{Large-scale flocculation experiments:} settling column

The settling column used for the experiments is described in Maggi et al. (2002) and Maggi (2005). A highly concentrated suspension is injected into the buffer tank on top of the settling column, where two counter-rotating vanes generate a uniform sediment distribution at the top of the settling tube. The concentration in the buffer tank is kept at the test concentration $c_{c}$ via a controlled system. The settling column is $4.7 \mathrm{~m}$ high and $280 \mathrm{~mm}$ in diameter. Herein, a homogeneous turbulence field, produced by an oscillating grid, induces flocculation. Turbulent shear $G$ values in the column range from 1 to $10 \mathrm{~s}^{-1}$, and $20 \mathrm{ppt}$ of sea salt was added to the suspension. Mud concentration is set to $c_{c}=0.165 \mathrm{~g} / \mathrm{l}$. The whole settling column is placed in a climatized room at $T=20^{\circ} \mathrm{C}$ to minimize temperature gradients and convective flows. Flocs are sampled from the settling column $0.93 \mathrm{~m}$ above the bottom, at the end of the oscillating grid. To compensate the hydrostatic pressure of the 4-m-high settling column, a dual-valve floc sample chamber (FSC) has been constructed. The tubular FSC is $24 \mathrm{~cm}$ in length and has an internal diameter of $18 \mathrm{~mm}$. The tube is connected to a valve located in the column outer wall and to a secondary water column with the free surface at the same height as the settling column.

Floc sizes and settling velocities of each sample are measured using the low intrusive, video-based laboratory spectral flocculation characteristics (LabSFLOC) instrument (Manning 2006). A picture of the different components of the LabSFLOC is shown in Fig. 1. The

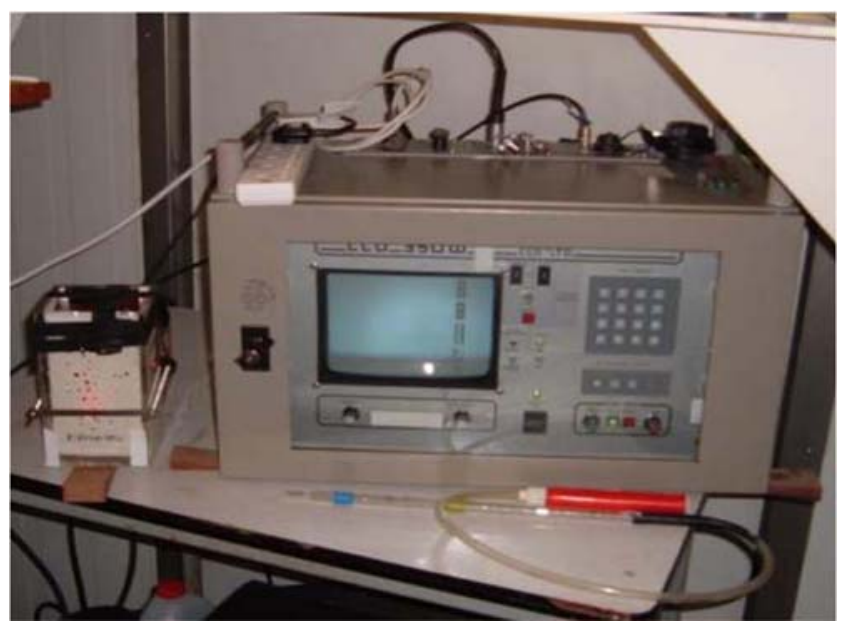

Fig. 1 Image of the LabSFLOC instrumentation: settling column (left), camera control unit (right) and modified floc extraction pipette (front right)
LabSFLOC is an adaptation for the laboratory of the INSSEV instrument developed for in situ observation by Fennessy et al. (1997), and the same camera system is used in both instruments. Flocs are transferred from the FSC to the LabSFLOC column using a modified pipette technique (e.g., Gratiot and Manning 2004). The settling flocs are monitored with a high-resolution monochromatic video camera, used to observe flocs as they settle in a settling column (Manning and Dyer 2002).

Floc settling images are initially recorded by an S-VHS video recorder at 25 frames per second. These analogue images are then digitized via a Zarbeco USB 2.0 Videolink PC card at a resolution of $640 \times 480$. An individual pixel represents $6.7 \mu \mathrm{m}$ (determined from calibration). Each floc video image time series was converted into separate AVI format files (one for each floc sample). The AVI files were then converted into a series of snap-shot images using a MatLab framegrabbing routine (AVI2JPEG) to provide a series of JPEG frames for each floc sample. The HR Wallingford "DigiFloc" software (version 1.0) was then used to obtain floc size and settling data from the series of JPEG frames per floc sample. Floc sizes are measured from the image size by overlaying an ellipse on each floc (provides major and minor axis floc dimensions: $L_{x}$ and $L_{y}$ ). Settling velocity is determined by measuring the vertical distance that the center of each floc travels between two frames. A spherical equivalent floc size $L_{i}$ was calculated as: $L_{i}=\left(L_{x} L_{y}\right)^{0.5}$. At a sediment concentration of $c=0.165 \mathrm{~g} / \mathrm{l}$, approximately 300-500 flocs are measured depending on the size of flocs.

\subsection{Data processing}

All flocculation data are divided into 100 size bins according to a geometrical series ranging between $10 \mathrm{~nm}$ and $10 \mathrm{~mm}$. Volume-based distributions are derived and normalized. The mean of the floc size distributions discussed in this paper is defined as:

$L_{\text {mean }}=\frac{\sum_{i} L_{i} V_{i}}{\sum_{i} V_{i}}$

where $L_{i}$ is the equivalent size of the particles in class $i$ and $V_{i}$ is the total volume of particles in that class.

The lower limit of the camera system used in the column $(20 \mu \mathrm{m})$ is much higher than the lower limit of the Malvern Instrument used in the mixing jar $(10 \mathrm{~nm})$. This may lead to a cut off of the distribution towards smaller flocs and to a larger mean size for the distribution observed with the camera system.

Most laser diffraction (LD) instruments obtain their particle (floc) sizes by employing the small-angle 
scattering method known as Mie scattering theory (Agrawal and Pottsmith 2000). This is an analytical solution of Maxwell's equations for the scattering of electromagnetic radiation by spherical particles. Scattering from a laser beam is observed at multiple angles. The applicability of Mie theory to LD devices has been examined by Agrawal et al. (2008). The multi-parameter Mie scattering equation is then mathematically inverted to determine size distribution, which would produce the observed multi-angle scattering (www.sequoiasci.com). From these calculations, a spherical equivalent particle diameter $L_{i}$ is produced, as all particles are assumed to be spherical.

LD devices are limited to measuring in low-turbidity environments, and can only indirectly measure particle sizes. LabSFLOC provides actual optical images of the flocs. By using gravimetrically determined SPM, the 3-D inferred floc sizes (eventually used to estimate floc dry mass) can be independently checked. LabSFLOC have generally demonstrated a more than $90 \%$ correlation between the computed and actual floc mass in a wide range of suspended concentrations (e.g., Manning and Dyer 2002; Manning et al. 2007a), which indicates that the 3-D inferred INSSEV and LabSFLOC floc size values are valid and can be compared with $\mathrm{LD}$-derived floc sizes.

A Malvern particle sizer adapted for underwater use (Bale and Morris 1987) was compared to INSSEV floc size measurements by Fennessy et al. (1997). Floc sizes were seen to be comparable up to a floc size of $500 \mu \mathrm{m}$. Fennessy et al. (1997) found that both the Malvern particle sizer and INSSEV measured similar floc shapes. In situ comparisons with INSSEV floc measurements and those from a Lasentec P100 (Law et al. 1997) were made during the COSINUS project deployments conducted within the upper Tamar estuary. Again, there was a good general agreement between the floc sizes measured by both instruments (Manning 2001).

\section{Results-small-scale experiments}

The purpose of these experiments is to investigate the effect of the suspension properties $(\mathrm{pH}$, salinity and $\mathrm{OMC}$ ) on flocculation. We use colloidal science on particles' charge and aggregation to predict flocculation. First, a study at different shear rates is done to verify that the influence of the properties of the suspension is the same at any $G$. We then select the more appropriate shear rate to use for the other mixing jar experiments, where $\mathrm{pH}$, salt concentration, and OMC are varied. The results of these experiments are then shown and compared to $\zeta$ potential measurements.

\subsection{Influence of shear rate}

Both aggregation and breakup depend on the shear rate $G$ as turbulent diff usion induces collisions between particles, which may result in aggregation, as well as shear stresses that may result in floc breakup (Hunt 1980). As a result of this, the mean floc size scales as the Kolmogorov microscale $\eta(\eta=\sqrt{v / G}$ with $v$ water viscosity). The time needed for the suspension to reach equilibrium, the flocculation time $T_{f}$, decreases with increasing $G$ because both aggregation and breakup rate increase.

The volume-based floc size distributions at equilibrium are plotted in Fig. 2a for different shear rates (suspension at $\mathrm{pH}=8$ with $9.5 \mathrm{ppt}$ of $\mathrm{MgCl}_{2}$ ). The total volume under the curves is the same for all distributions. The floc size is plotted in logarithmic scale to better represent the wide range of floc sizes. All distributions show a small peak at the smaller classes and another at the larger ones. When the shear rate decreases from $G=101 \mathrm{~s}^{-1}$ to $G=23 \mathrm{~s}^{-1}$, both peaks shift towards the larger classes as $L_{\text {mean }}$ increases. Although the maximum floc size observed at $G=12 \mathrm{~s}^{-1}$ is larger than that at $G=23 \mathrm{~s}^{-1}$, the distribution in this case is unimodal with a tail towards the smaller particles: possibly, flocculation of small particles is not complete. The evolution in time of $L_{\text {mean }}$ is plotted in Fig. $2 b$ for different shear rates. The experiments are continued until a steady state has been reached, and the time needed to reach the equilibrium is close to $2 \mathrm{~h}$ for all $G \geq 23 \mathrm{~s}^{-1}$.

The "obscuration" is a measure of the amount of laser light lost within the sample. The obscuration decreases with increasing $L_{\text {mean }}$ and can be used to estimate the amount of sediment in suspension. At constant sediment concentration, the total cross-sectional area decreases when the floc size increases. The evolution in time of the obscuration as a function of $L_{\text {mean }}$ is shown for the same suspension in Fig. 2c. For $G \geq 23 \mathrm{~s}^{-1}$, the obscuration decreases slightly as $L_{\text {mean }}$ increases. At $G=12 \mathrm{~s}^{-1}$, a steep decrease of the obscuration is observed. This suggests that settling is taking place in the mixing jars at $G=12 \mathrm{~s}^{-1}$.

The water depth in the jar is small $(8 \mathrm{~cm})$, and if particles are not kept in suspension by the rotating paddle, they settle before the flocculation process is complete. As observed in Fig. 2c, at $G=12 \mathrm{~s}^{-1}$, particles are no longer kept in suspension by the paddle, and their residence time $T_{r}$ is limited by settling. The flocculation time $T_{f}$ is large at low $G$ since the collision frequency between particles is small. The flocculation time also depends on the properties of the suspension: $T_{f}$ is larger for more stable suspensions than for unstable 

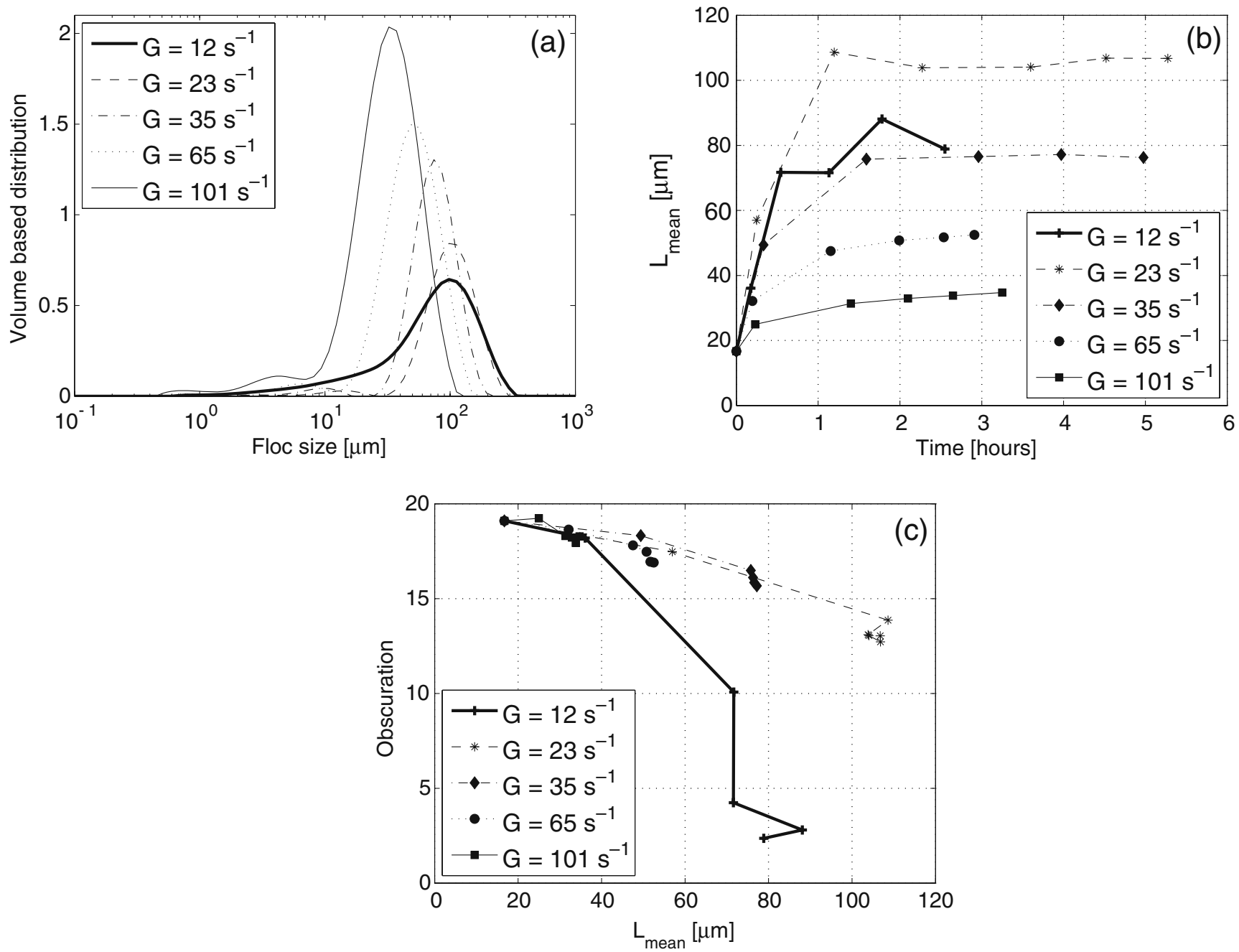

Fig. 2 Floc size distribution (a) and time evolution of $L_{\text {mean }}(\mathbf{b})$ for different shear rates. Laser obscuration as a function of $L_{\text {mean }}(\mathbf{c})$. Suspension at $\mathrm{pH}=8$ and with $9.5 \mathrm{ppt}$ of $\mathrm{MgCl}_{2}$

ones, as the collision efficiency is smaller. As flocs settle, the suspended sediment concentration decreases, and this leads to a decrease of the equilibrium floc size. Moreover, when flocs settle before the population reaches equilibrium $\left(T_{r}<T_{f}\right)$, the observed floc size is smaller than the equilibrium floc size.

Similar results have been found by Serra et al. (2008) and Colomer et al. (2005), who observed that the mean floc size increases with $G$ at low shear. They used a mixing jar similar to ours and latex particles with the same density as the suspension (not affected by settling). The authors argue that the effect of shear rate at low $G$ is to induce particle collisions and, therefore, aggregation. This is in contrast with our interpretation of the results, as well as with the theoretical considerations by Winterwerp (1998). We decided therefore to repeat the experiments by Serra et al. (2008) both with non-buoyant particles and with particles heavier than the suspension. The results of these experiments are presented in Mietta et al. (2009) and support our hypothesis, showing the effect of settling when particles are heavier than water at $G<G^{*}$. $G^{*}$ depends on the size and density of the flocs, on the shape of the jar and the mixing efficiency of the propeller, and on the flocculation time of the suspension $T_{f}$. By testing our specific setup with different suspensions, we concluded that $T_{r}>T_{f}$ for all $G>G^{*}=35 \mathrm{~s}^{-1}$. $G^{*}$ is the shear rate used for investigation of the role of the properties of the suspension on flocculation.

$L_{\text {mean }}$ is plotted as a function of shear rate for different suspensions in Fig. 3a, where the Kolmogorov microscale is plotted for reference as well. The floc size and the Kolmogorov microscale vary similarly with $G$ as observed by Fettweis et al. (2006) and van der Lee et al. (2009): for a given suspension, the ratio between the Kolmogorov microscale and the floc size is the same 


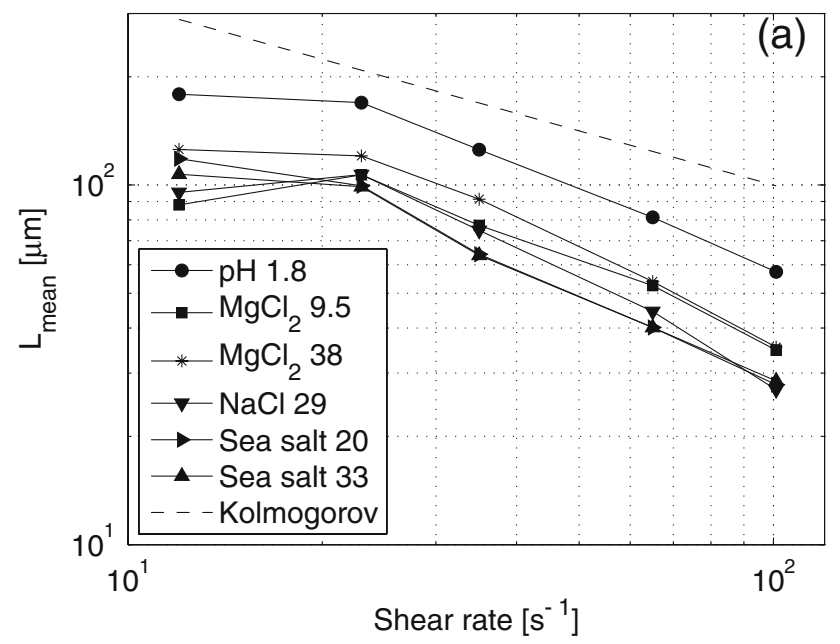

Fig. $3 L_{\text {mean }}$ as a function of shear rate (a) and time evolution of $L_{\text {mean }}$ at $G=35 \mathrm{~s}^{-1}$ (b) for different suspensions. The numbers indicate, respectively, $\mathrm{pH}$ and salt concentrations in ppt. At low

for all $G$. At a given shear rate, as mentioned above, the floc size depends on the charge of the particles, the $\mathrm{OMC}$, the salinity, and the $\mathrm{pH}$. At $G=12 \mathrm{~s}^{-1}$, the equilibrium $L_{\text {mean }}$ is smaller or equal to the value observed at $G=23 \mathrm{~s}^{-1}$. This is due to the settling of particles, the effect of which is more pronounced for more stable suspensions $\left(\mathrm{MgCl}_{2}\right.$ at $9.5 \mathrm{ppt}$ and sea salt at $20 \mathrm{ppt}$ ), as the flocculation time at low $G$ is larger. The time evolution of $L_{\text {mean }}$ at $G=35 \mathrm{~s}^{-1}$ varies little with the properties of the suspension. The initial growth rate is slightly higher for more unstable suspensions $(\mathrm{pH}=1.8$ and no added salt), see Fig. $3 \mathrm{~b}$. The time needed to reach equilibrium is close to $2 \mathrm{~h}$ for all suspensions.

\section{$3.2 \zeta$ potential measurements}

The $\zeta$ potential of the mud used is plotted in Fig. 4a and $\mathrm{b}$ for different $\mathrm{pH}$ and salt concentrations, respectively. The $\zeta$ potential increases very little with $\mathrm{pH}$ at $\mathrm{pH}>4$, and it is close to $0 \mathrm{mV}$ at $\mathrm{pH}=2$. The $\zeta$ potential also increases with increasing salt concentration. At the same salt concentration, the $\zeta$ potential is larger for the suspension with $\mathrm{MgCl}_{2}$ than for the suspension with $\mathrm{NaCl}$, Fig. 4b. Sea salt is mainly composed of $\mathrm{NaCl}$, to which $\mathrm{KCl}, \mathrm{MgCl}_{2}$, and $\mathrm{CaCl}_{2}$ are added in different proportions: the $\zeta$ potential of the suspension with sea salt is in between those of the suspensions with $\mathrm{NaCl}$ and $\mathrm{MgCl}_{2}$. The variation of the mud $\zeta$ potential with salt concentration and $\mathrm{pH}$ is identical to that observed for the clay constituents of the mud. For all the clays, the $\zeta$ potential increases with increasing salt

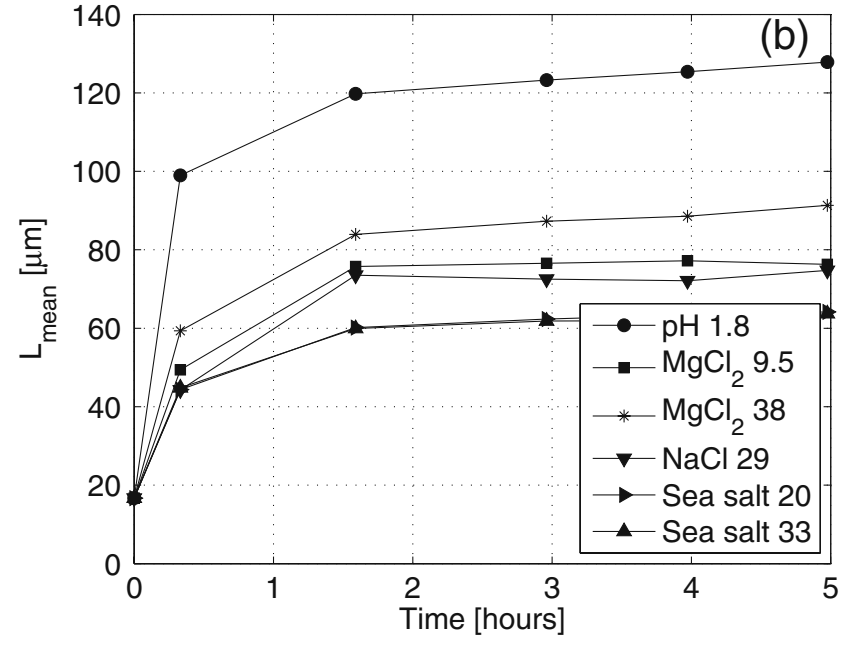

$\mathrm{pH}$, no salt is added to the suspension and suspensions with different salts are at $\mathrm{pH}=8$

concentration and decreasing $\mathrm{pH}$. The increase of the $\zeta$ potential is larger upon addition of divalent salt than of monovalent salt (Sondi et al. 1996; Kosmulski 2006; Tombacz and Szekeres 2004; Tomback and Szekeres 2006; Mietta et al. 2009).

We note that, for suspension at $\mathrm{pH}=8$ and added $\mathrm{MgCl}_{2}, L_{\text {mean }}=90 \mu \mathrm{m}$ when $\zeta=8 \mathrm{mV}$ and $L_{\text {mean }}=$ $60 \mu \mathrm{m}$ when $\zeta=-8 \mathrm{mV}$. This indicates that the repartition of charges and organic matter on the particles depends on the salt concentration. If it would not be the case, $L_{\text {mean }}$ would be the same regardless of the sign of the $\zeta$ potential.

\subsection{Influence of salinity and $\mathrm{pH}$}

The equilibrium $L_{\text {mean }}$ of flocs is shown in Fig. $4 \mathrm{c}$ and $\mathrm{d}$ as a function of $\mathrm{pH}$ or salt concentration. A decrease of the $\mathrm{pH}$ implies a rapid increase of the particles' size due to rapid flocculation promoted by the chemical interactions (protonation/deprotonation) on the clay surfaces, Fig. 4c.

For different salt concentrations, $L_{\text {mean }}$ shows a behavior similar to that of the $\zeta$ potential: it increases for increasing salt concentration, Fig. 4d. Flocculation enhancement is stronger for divalent salts than for monovalent salts, at equal concentration. The suspension with sea salt varies very little for salt concentrations larger than 15 ppt. A similar behavior was observed by Krone (1963) and Migniot (1968), who did not observe variations of floc size at salinities higher than 3 $10 \mathrm{ppt}$. This value was found to depend on the sediment concentration. 
Fig. $4 \zeta$ potential $(\mathbf{a}, \mathbf{b})$ and equilibrium $L_{\text {mean }}$ at $G=35 \mathrm{~s}^{-1}(\mathbf{c}, \mathbf{d})$ as a function of $\mathrm{pH}(\mathbf{a}, \mathbf{c})$ or salt concentration $(\mathbf{b}, \mathbf{d})$. Triangles indicate $\mathrm{MgCl}_{2}$, squares indicate $\mathrm{NaCl}$, and circles indicate sea salt. At low $\mathrm{pH}$, no salt is added to the suspension, and suspensions with different salts are at $\mathrm{pH}=8$
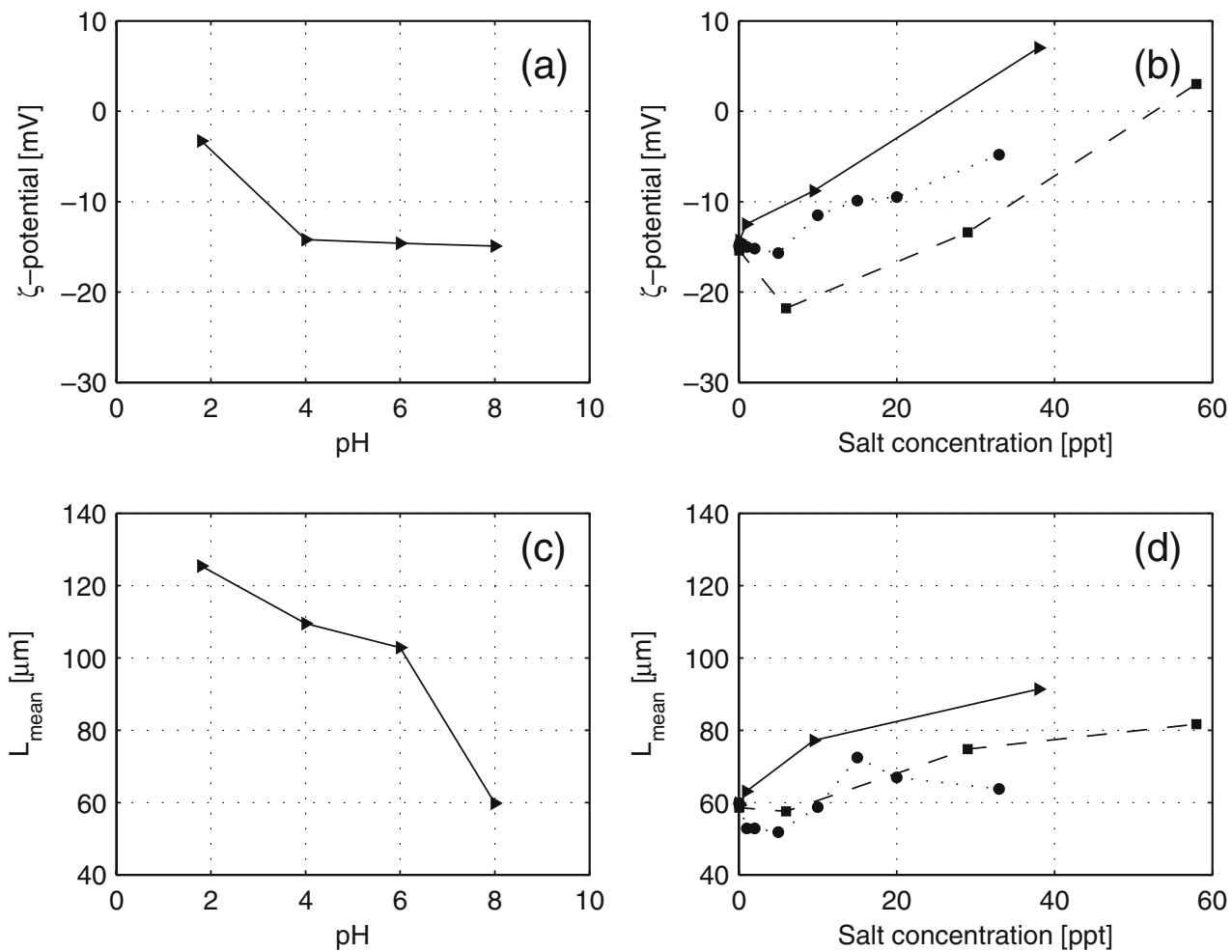

A few equilibrium floc size distributions obtained at $G=35 s^{-1}$ for different $\mathrm{pH}$ values and salts are plotted in Fig. 5. All suspensions are bimodal with a small peak corresponding to the primary particles, and another corresponding to large flocs. Both peaks are shifted towards larger floc sizes when the suspension is more unstable.

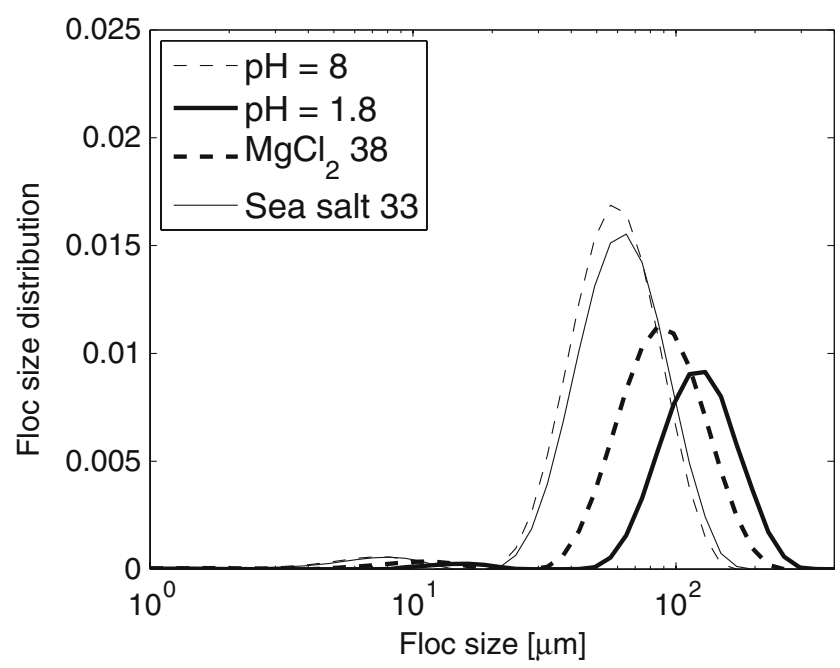

Fig. 5 Equilibrium floc size distribution of different suspensions at $G=35 s^{-1}$. At low $\mathrm{pH}$, no salt is added to the suspension and suspensions with different salts are at $\mathrm{pH}=8$
The equilibrium mean sizes for all suspensions are shown in Fig. 6 as a function of the $\zeta$ potential. When salt is added to the suspension $(\mathrm{pH}=8)$, the mean size of flocs increases linearly with the $\zeta$ potential. In addition, the mean floc size is the same for a given $\zeta$ potential for any salt. The fit by the dotted line plotted

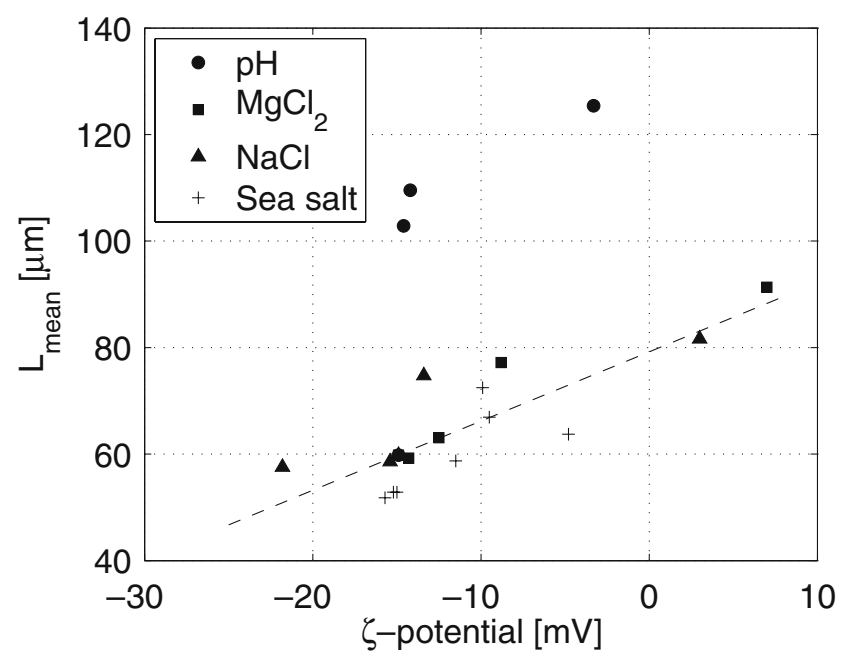

Fig. 6 Equilibrium $L_{\text {mean }}$ at $G=35 \mathrm{~s}^{-1}$ as a function of the $\zeta$ potential for different suspensions. The trend line is explained in the text. $\mathrm{pH}$ indicates a suspension at low $\mathrm{pH}$ and no added salt, $\mathrm{MgCl}_{2}, \mathrm{NaCl}$, and sea salt refer, respectively, to suspensions at $\mathrm{pH}=8$ and different concentrations of $\mathrm{MgCl}_{2}, \mathrm{NaCl}$, and sea salt 
in Fig. 6 is $L_{\text {mean }}=L_{\text {mean }, 0}+c_{\zeta}\left(\zeta-\zeta_{0}\right)$, where $\zeta$ is the $\zeta$ potential, $L_{\text {mean }, 0}$ and $\zeta_{0}$ represent a reference point, and $c_{\zeta}=1.31 / \mathrm{mV}$ is an interpolation coefficient. The correlation coefficient for this interpolation is $R^{2}=0.695$. The three points at low $\mathrm{pH}$ have not been considered here. The slope of this line depends on the salt concentration and, therefore, on the charge of the particles. The intercept of the line with $\zeta=0 \mathrm{mV}$ depends on the shear rate, sediment concentration, primary particles size distribution and OMC. For given conditions, it is therefore possible to derive $L_{\text {mean }}$ at different salt concentrations from the measure of the equilibrium floc size and of the $\zeta$ potential at a given salinity.

When the $\mathrm{pH}$ is decreased (no added salt), flocs are always larger than those formed upon addition of salt. As for saline suspensions, $L_{\text {mean }}$ increases with the $\zeta$ potential. These results are in agreement with electrokinetic considerations and show how a simple measure of the $\zeta$ potential can be used to predict the flocculation behavior.

\subsection{Influence of organic matter content}

OMC influences both the collision efficiency and the floc strength (Winterwerp and van Kesteren 2004). This is reflected in Fig. 7a, where the variation of the equilibrium floc size with $\mathrm{OMC}$ is shown. The size of a completely deflocculated suspension, where flocs have been broken through ultrasonic treatment, is plotted for reference. If all other conditions are equal (shear rate, $\mathrm{pH}$, and salt concentration), the mean floc size increases with increasing OMC. The equilibrium floc size of the mud suspension treated with hydrogen peroxide $(\mathrm{OMC}=0)$ is very similar to the one of a suspension completely deflocculated by ultrasonic treatment. This shows that mud in tap water with no organic matter is rather stable. The same has been observed for kaolinite in Mietta et al. (2009). Charged particles in tap water are very unlikely to aggregate if no organic matter is present. The equilibrium FSDs at low OMC are monomodal with a small tail towards smaller particles; when OMC increases, the larger peak shifts towards larger particles and, at $\mathrm{OMC}=6.52 \%$, a bimodal distribution can be observed (Fig. 7b).

Figure 8 shows the mean floc sizes for mud, mud with no organic matter, and kaolinite in different suspensions. $L_{\text {mean }}$ of mud with organic matter is always larger than the one of mud treated with hydrogen peroxide, which in turn is very similar to the one of kaolinite (Mietta et al. 2009). Moreover, $L_{\text {mean }}$ of kaolinite and mud with and without organic matter responds in the same way to the changes in $\mathrm{pH}$ and salt concentration of the suspension. This is promising since our aim is to seek a general response of the flocculation behavior to changes in chemistry for complex sediments formed by organic matter and clays at different ratios.

\section{Results - from small to large scale}

Two data-sets from two different experiments in the settling column are discussed in this section. The first experiment was performed at a shear rate $G=2 \mathrm{~s}^{-1}$ and sediment concentration $c=0.165 \mathrm{~g} / \mathrm{l}$. This experiment started with no sediment in the column and the data-set S2 was measured $25 \mathrm{~h}$ after the beginning of
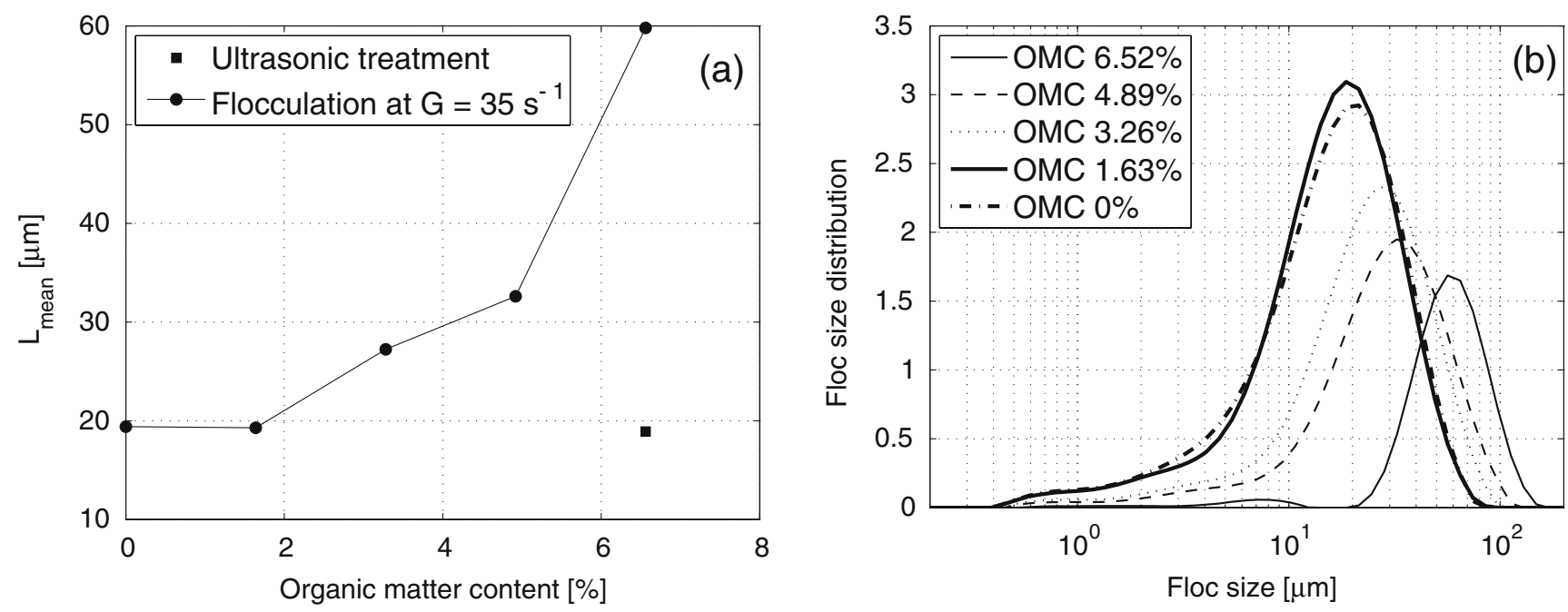

Fig. 7 Equilibrium $L_{\text {mean }}(\mathbf{a})$ and floc size distributions (b) at different OMCs. $L_{\text {mean }}$ of mud after ultrasonic treatment is plotted for reference in a. The shear rate is $G=35 \mathrm{~s}^{-1}$ and the $\mathrm{OMC}$ is written in the legends. All suspensions are at $\mathrm{pH}=8$ with no added salt 


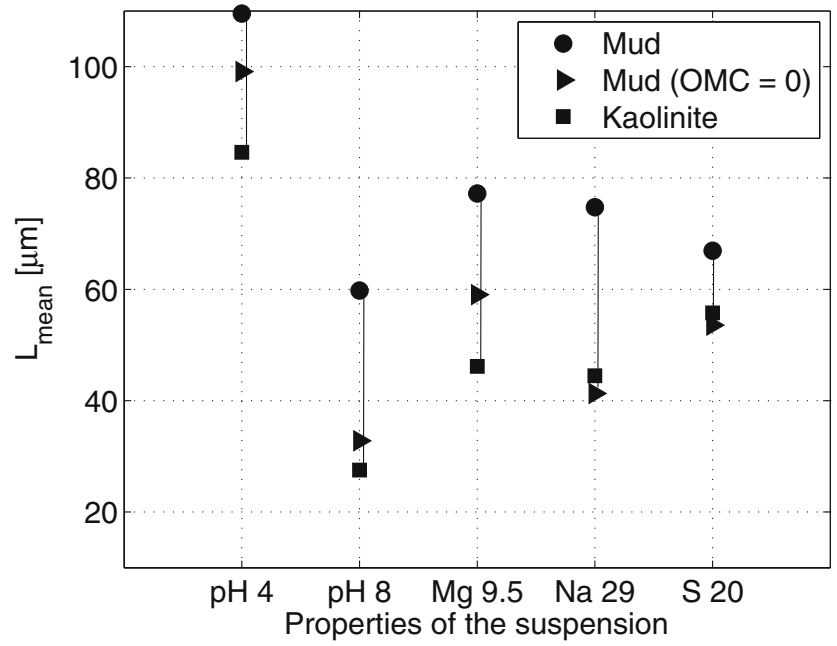

Fig. 8 Comparison between equilibrium $L_{\text {mean }}$ of mud with organic matter (circles), mud without organic matter (triangles), and kaolinite (squares) for different ambient water properties. $\mathrm{Mg}, \mathrm{Na}$, and $\mathrm{S}$ refer, respectively, to suspensions at $\mathrm{pH}=8$ and added $\mathrm{MgCl}_{2}, \mathrm{NaCl}$, and sea salt. The numbers indicate the $\mathrm{pH}$ or the salt concentration in ppt. Shear rate $G=35 \mathrm{~s}^{-1}$, mass concentration $c_{\text {mud }}=0.12 \mathrm{~g} / \mathrm{l}$ and $c_{\text {kao }}=0.135 \mathrm{~g} / 1$

the sediment injection and of the grid oscillation. The sediment concentration was observed to be uniform through the column after $20 \mathrm{~h}$, we consider the flocculation experiment to start after this moment. The second experiment was started right after the first one, and the initial population is the one measured in S2. This experiment was performed at a shear rate $G=10 \mathrm{~s}^{-1}$ and sediment concentration $c=0.195 \mathrm{~g} / \mathrm{l}$. The data-set $\mathrm{S} 10$ is measured $3.5 \mathrm{~h}$ after the increase in shear rate.

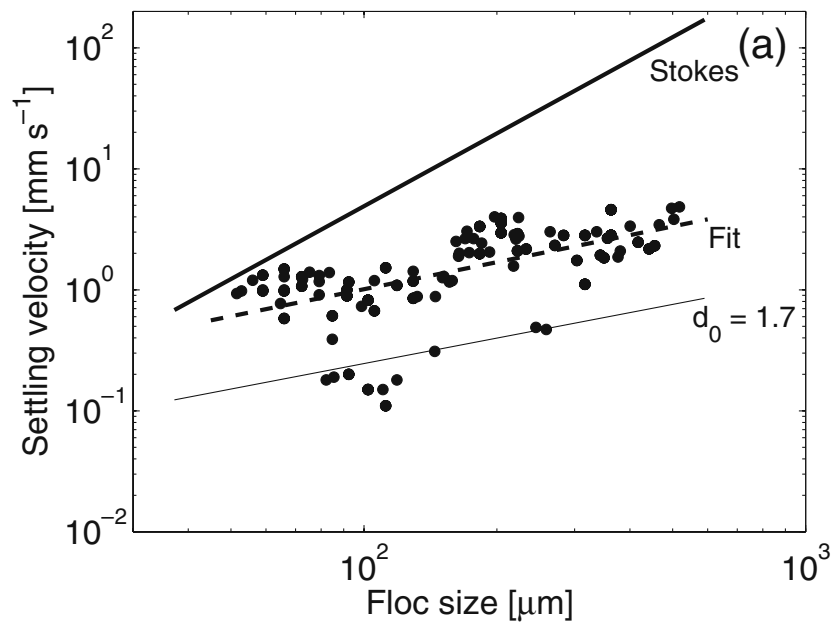

Fig. 9 Settling velocity distributions as a function of the floc size for settling column data. Suspension at $\mathrm{pH}=8$ with $20 \mathrm{ppt}$ of sea salt and sediment concentration $c=0.165 \mathrm{~g} / 1$ for $G=2 \mathrm{~s}^{-1}$ (a) and $c=0.195 \mathrm{~g} / 1$ for $G=10 \mathrm{~s}^{-1}$ (b). The settling velocity
Both experiments have been done on a suspension at $\mathrm{pH}=8$ with $20 \mathrm{ppt}$ of added sea salt.

Figure 9 shows the floc settling velocity distributions as a function of the floc size for the two different data sets. The lines plotted represent the settling velocity computed for fractal flocs for different fractal dimensions $d_{0}$ with the equation proposed by Winterwerp (1998):

$\omega_{s}=a \frac{\left(\rho_{s}-\rho_{w}\right) g}{\mu} L_{p}^{3-d_{0}} \frac{L^{d_{0}-1}}{1+0.15 R e^{0.687}}$,

where $a \approx 1 / 18$ is a shape parameter, $\rho_{s}$ and $\rho_{w}$ are the specific density of the sediment and water respectively, $g$ is the gravity acceleration and $\mu$ is the dynamic viscosity of water. $L_{p}=1 \cdot 10^{-5} \mathrm{~m}$ is the size of the primary particles. This value is the mean size of the primary particles size distribution. $\operatorname{Re}=\frac{\omega_{s} L}{v}$ with $v$ kinematic viscosity of water as the floc Reynolds number. The values of floc size and settling velocity observed are of the same order as the ones observed in situ by Manning et al. (2007b) in similar conditions. The density of the particles $\left(d_{0} \approx 1.7\right)$ is smaller than usually observed in situ $\left(d_{0} \approx 2\right)$. This can be due to the shear history of flocs, as well as to the nature and amount of the organic matter. However, the data are rather scattered and the interpolating line may not fully represent the properties of the observed flocs.

The residence time in the settling column depends on the duration of the experiment and on the time needed by the particles to settle through the column. This can be estimated from the observed settling velocity of flocs. The settling velocity varies between 0.2 and

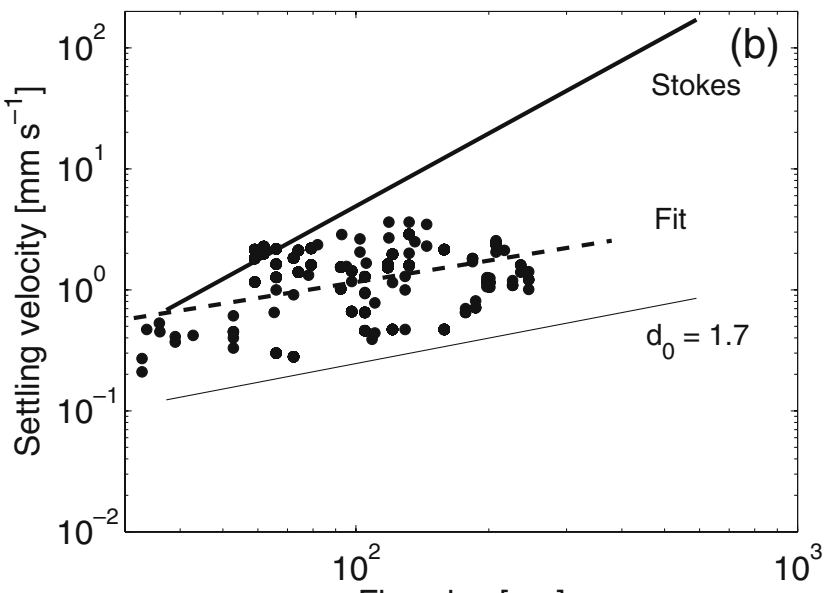

Floc size $[\mu \mathrm{m}]$

computed with Eq. 5 and $d_{0}=1.7$ is plotted for reference. Stokes refers to the settling velocity computed for solid spheres using the Stokes law 
$4 \mathrm{~mm} / \mathrm{s}$ for S2 and 0.1 and $4 \mathrm{~mm} / \mathrm{s}$ for $\mathrm{S} 10$. These settling velocities correspond approximately to a residence time $T_{r}$ varying between $16 \mathrm{~min}$ and $5.5 \mathrm{~h}$ for $\mathrm{S} 2$ and $16 \mathrm{~min}$ and $11 \mathrm{~h}$ for $\mathrm{S} 10$.

For the first experiment, the initial floc size is smaller than the equilibrium size as the experiment starts from a completely deflocculated suspension (as in the mixing jar experiments). The dominant mechanism in this experiment is, therefore, aggregation. From the jar test observations with the same suspension ( $20 \mathrm{ppt}$ of sea salt and $\mathrm{pH}=8$ ), the time needed to reach equilibrium at $G=35 \mathrm{~s}^{-1}$ is $2 \mathrm{~h}$. The flocculation time of a saline suspension ( $\mathrm{pH}=8$ and $9.5 \mathrm{ppt}$ of added $\mathrm{MgCl}_{2}$ ) varies little with $G$, see Fig. 2b. From this, we deduce that the suspension should be at equilibrium after $5.5 \mathrm{~h}$ in the settling tube.

For the second experiment, the initial floc size is larger than the equilibrium size. The dominant mechanism in this experiment is therefore breakup. The flocculation time is, in this case, smaller than for the first experiment: both aggregation and breakup rates scale as the size of flocs and the initial floc size is larger than for the first experiment (Winterwerp 1998). We therefore expect that the population measured after $3.5 \mathrm{~h}$ for $\mathrm{S} 10$ is at equilibrium.

The equilibrium $L_{\text {mean }}$ for estuarine conditions ( 20 ppt sea salt and $\mathrm{pH}=8$ ) is shown for both smallscale and large-scale experiments in Fig. 10. A wide range of shear rates is taken into account, and the Kolmogorov microscale is plotted for reference as well. All data are smaller than the Kolmogorov microscale,

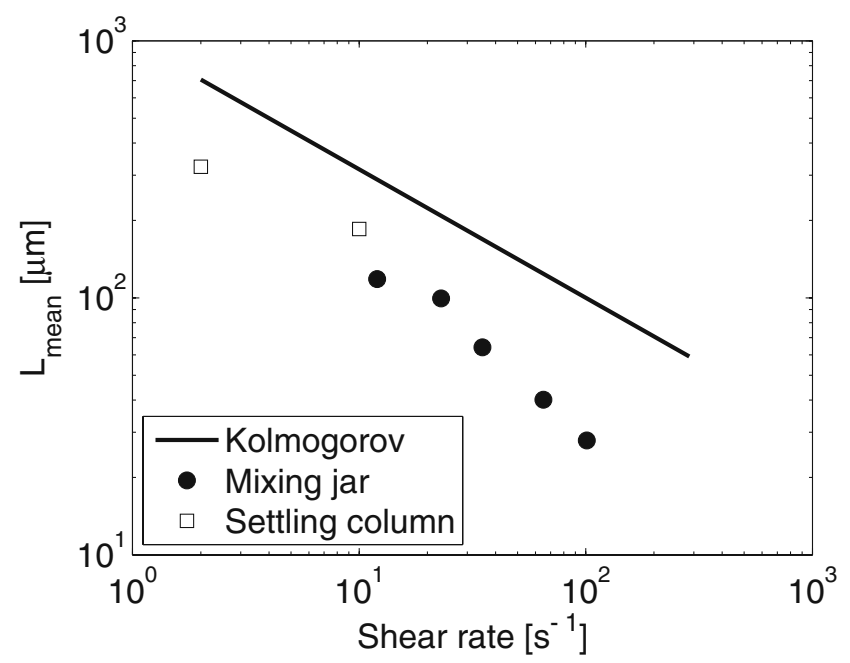

Fig. 10 Equilibrium $L_{\text {mean }}$ as a function of the shear rate. Kolmogorov microscale is plotted for comparison. Suspension at $\mathrm{pH}=8$ with $20 \mathrm{ppt}$ of sea salt and sediment concentration $c=0.165 \mathrm{~g} / 1$ for $G=2 \mathrm{~s}^{-1}, c=0.195 \mathrm{~g} / 1$ for $G=10 \mathrm{~s}^{-1}$ and $c=0.12 \mathrm{~g} / 1$ for $G \geq 12 \mathrm{~s}^{-1}$

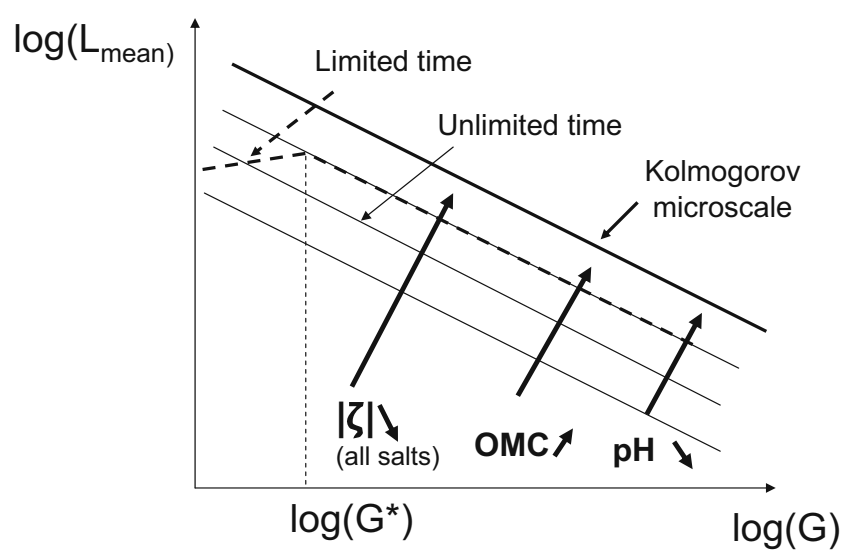

Fig. 11 Schematic representation of the variation of $L_{\text {mean }}$ with the shear rate and the properties of the suspension. Solid lines: unlimited residence time, dashed line: limited residence time. The critical value $G^{*}$ depends on the residence time and flocculation behavior. The size of flocs increases for increasing OMC, decreasing $\mathrm{pH}$, and decreasing absolute value of the $\zeta$ potential

and $L_{\text {mean }}$ decreases with $G$. For a given suspension, the ratio between the Kolmogorov microscale $\eta$ and the mean floc size $L_{\text {mean }}$ does not vary with the shear rate for both the small-scale mixing jars and the largescale settling column. $L_{\text {mean }}$ found with the mixing jar at $G=12 \mathrm{~s}^{-1}$ and the one obtained with the settling column at $G=10 \mathrm{~s}^{-1}$ are very close. As discussed in Section 3.1, $L_{\text {mean }}$ measured in the mixing jar at $G=12 \mathrm{~s}^{-1}$ is slightly smaller than the equilibrium size because of settling. A combination of the two experimental devices (mixing jar and settling column) allows, therefore, to measure the equilibrium floc size over a wide range of shear rates.

\section{Conclusions}

Small-scale experiments in the mixing jar show that $L_{\text {mean }}$ and the Kolmogorov microscale vary in a similar way with $G$ for suspensions at different $\mathrm{pH}$ and salt concentrations. For a given shear rate, the particle size depends on the properties of the suspension $(\mathrm{pH}$, salt concentration, and OMC). By means of a wide range of flocculation experiments, we found a relation between the $\zeta$ potential of the particles and their flocculation behavior at high shear rate $\left(G=35 \mathrm{~s}^{-1}\right)$ : when salt is added to the suspension $(\mathrm{pH}=8)$, the equilibrium size of flocs increases when the $\zeta$ potential decreases in magnitude independently of the salt used. For a given $\zeta$ potential, $L_{\text {mean }}$ is larger at low $\mathrm{pH}$ than at high $\mathrm{pH}$ for any salt. The $\mathrm{pH}$ is rather constant in estuaries and oceans ( $\mathrm{pH}=6-8)$; therefore, the mean floc size can be predicted from the measure of the $\zeta$ potential. While 
$L_{\text {mean }}$ is strongly dependent on the properties of the suspension, the time needed to reach equilibrium is rather constant and is, in most cases, smaller than the one observed for kaolinite suspensions in Mietta et al. (2009).

Another parameter affecting floc size is the OMC. Organic matter increases both collision efficiency and floc strength, and we observed an increase of the equilibrium floc size in the mixing jar experiments. Moreover, the response to changes in suspension properties is similar for mud, mud with no organic matter, and kaolinite. This suggests that electrokinetic and flocculation studies on clays can improve our understanding of the effect of the suspending medium chemistry on the flocculation of complex cohesive sediments. A further improvement of this study would be to investigate the effect of not only the amount but also the composition and properties of the organic matter (polymers in particular) on flocculation.

From the considerations above, a schematic representation of the flocculation behavior of mud for different shear rates and suspension properties can be drawn. The size of flocs is always smaller than the Kolmogorov microscale and the equilibrium floc size increases when the $\zeta$ potential of the particles decreases in magnitude or the OMC increases. Moreover, when the $\mathrm{pH}$ of the suspension decreases, $L_{\text {mean }}$ increases (Fig. 11). If the residence time of flocs is limited, a shear rate $G^{*}$ can be found below which $L_{\text {mean }}$ varies no longer with $G$ as the Kolmogorov microscale. At limited residence time, $L_{\text {mean }}$ no longer represents the equilibrium floc size at $G<G^{*}$.

Acknowledgements This research is supported by the Dutch Technology Foundation STW, applied science division of NWO, and the Technology Program of the Ministry of Economic Affairs. The authors are grateful to Deltares for allowing the use of the Malvern instruments. Dr. Manning's contribution to the laboratory settling column experiments was primarily funded by the Coasts and Estuaries Group at HR Wallingford Ltd.

Open Access This article is distributed under the terms of the Creative Commons Attribution Noncommercial License which permits any noncommercial use, distribution, and reproduction in any medium, provided the original author(s) and source are credited.

\section{References}

Agrawal YC, Pottsmith HC (2000) Instruments for particle size and settling velocity observations in sediment transport. Mar Geol 168(1-4):89-114

Agrawal YC, Whitmire A, Mikkelsen OA, Pottsmith HC (2008) Light scattering by random shaped particles and consequences on measuring suspended sediments by laser diffraction. J Geophys Res 113:C04023
Bale AJ, Morris AW (1987) In-situ measurement of particle size in estuarine waters. Estuar Coast Shelf Sci 24: 253-263

Bouyer D, Escudié R, Liné A (2005) Experimental analysis of hydrodynamics in a jar-test. Process Saf Environ Prot 83(B1):22-30

Burt TN (1986) Field settling velocities in estuarine muds. Estuarine cohesive sediment dynamics. Springer, Berlin

Burton JD, Liss PS (1976) Estuarine chemistry. Academic, London (a subsidiary of Harcourt Brace Jovanovich publishers)

Chassagne C, Mietta F, Winterwerp JC (2009) Electrokinetic study on kaolinite suspensions. J Colloid Interface Sci 336(1):352-359

Colomer J, Peters F, Marrasé C (2005) Experimental analysis of coagulation of particles under low shear flow. Water Res 39:2994-3000

Eisma D, Bernard P, Cadée GC, Ittekkot V, Kalf J, Laane R, Martin JM, Mook WG, van Put A, Schumacher T (1991) Suspended matter particle size in some west-european estuaries; part II: a review on floc formation and break-up. Neth J Sea Res 28(3):215-220

Fennessy MJ, Dyer KR, Huntley DA, Bale AJ (1997) Estimation of settling flux spectra in estuaries using INSSEV. In: Burt N, Parker R, Watts J (eds) Cohesive sediments-proc. of INTERCOH conf. Wiley, Chichester, pp 87-104

Fettweis M, Francken F, Pison V, Van den Eynde D (2006) Suspended particulate matter dynamics and aggregate sizes in a high turbudity area. Mar Geol 235:63-74

Gratiot N, Manning AJ (2004) An experimental investigation of floc characteristics in a diff usive turbulent flow. In: Ciavola P, Collins MB (eds) Sediment transport in European Estuaries, journal of coastal research, SI 41, pp 105-113

KIWA (1976) Bekerglasproef voor coagulatie. 1. Mengtijden en G-waarden. KIWA internal report

Kosmulski M, Dahlten P (2006) High ionic strength electrokinetics of clay minerals. Colloids Surf A Physicochem Eng Asp 291:212-218

Krone RB (1963) A study of rheologic properties of estuarial sediments. Tech Bull 7 commitee of tidal hydraulics

Kruyt HR (1983) Colloid science, vol 1. Elsevier, Amsterdam

Hunt JR (1980) Prediction of oceanic particle size distributions from coagulation and sedimentation mechanism. Am Chem Soc 189:243-257

Law DJ, Bale AJ, Jones SE (1997) Adaptation of focused beam reflectance measurement to in-situ particle sizing in estuaries and coastal waters. Mar Geol 140:47-59

Leifeld J, Kogel-Knabner I (2001) Organic carbon and nitrogen in fine soil fractions after treatment with hydrogen peroxide. Soil Biol Biochem 33:2155-2158

Maggi F (2005) Flocculation dynamics of cohesive sediments. PhD Thesis TU Delft, Delft

Maggi F, Winterwerp JC, Fontijn HL, van Kesteren WGM, Cornelisse JM (2002) A settling column for turbulenceinduced flocculation of cohesive sediments. In: Wahl TL, Pugh CA, Oberg KA, Vermeyen TB (eds) Proceedings of HMEM2002 Conference, Estes Park, Colorado, paper 93. doi:10.1061/40655(2002)34

Manning AJ (2001) A study of the effects of turbulence on the properties of flocculated mud. $\mathrm{PhD}$ thesis, Institute of marine studies, University of Plumouth, $282 \mathrm{p}$

Manning AJ (2006) LabSFLOC - a laboratory system to determine the spectral characteristics of flocculating cohesive sediments. HR Wallingford Technical Report, TR 156

Manning AJ, Dyer KR (2002) The use of optics for the in-situ determination of flocculated mud characteristics. J Opt A Pure Appl Opt 4:S71-S81 
Manning AJ, Friend PL, Prowse N, Amos CL (2007) Preliminary Findings from a Study of Medway Estuary (UK) Natural Mud Floc Properties Using a Laboratory Mini-flume and the LabSFLOC system. Continental Shelf Research, BIOFLOW SI, 1080-1095. doi:10.1016/j.csr.2006.04.011

Manning AJ, Martens C, de Mulder T, Vanlede J, Winterwerp JC, Ganderton P, Graham GW (2007) Mud floc observations in the turbidity maximum zone of the Scheldt Estuary during neap tides. J Coast Res SI 50:832-836

Mietta F, Chassagne C, Winterwerp JC (2009) Flocculation of kaolinite by turbulend shear as a function of its electrokinetic properties. J Colloid Interface Sci 336(1): 134-141

Migniot C (1968) Etude des propriétés physiques de différents sédiments très fins et de leur comportement sous des actions hydrodynamiques. La Houille Blanche 23:591-620

Mikkelsen OA (2002) Examples of spatial and temporal variations of some fine-grained suspended particle characteristics in two Danish coastal water bodies. Oceanol Acta 25: 39-49

Nagata S (1975) Mixing: principles and applications. Halsted Wiley, Chichester

Serra T, Colomer J, Logan BE (2008) Efficiency of different shear devices on flocculation. Water Res 42:1113-1121

Sondi I, Biscan J, Pradvic V (1996) Electrokinetics of pure clay minerals revisited. J Colloid Interface Sci 178:514-522
Tennekes H, Lumley J (1972) A first course into turbulence. MIT, Cambridge

Tombacz E, Szekeres M (2004) Colloidal behaviour of aqueous montomorillonite suspensions: the specific role of $\mathrm{pH}$ in the presence of indifferent electrolytes. Appl Clay Sci 27: $75-94$

Tombackz E, Szekeres M (2006) Surface charge of kaolinite in aqueous suspension in comparison with montmorillonite. Appl Clay Sci 34:105-124

van der Lee WTB (2000) Temporal variation of flocs size and settling velocity in the Dollard estuary. Cont Shelf Res 20: 1495-1511

van der Lee EM, Bowers DG, Kyte E (2009) Remote sensing of temporal and spatial patterns of suspended particle size in the Irish Sea in relation to the Kolmogorov microscale. Cont Shelf Res 29:1213-1225

van Leussen W (1999) The variability of settling velocities of suspended fine-grained sediment in the Ems estuary. J Sea Res 41:109-118

Winterwerp JC (1998) A simple model for turbulence induced flocculation of cohesive sediment. J Hydraul Eng Res 36(3):309-326

Winterwerp JC, van Kesteren W (2004) Introduction to the physics of cohesive sediment in the marine environment. Development in sedimentology. Elseiver, Amsterdam 